merely transitory change, ten full pulsations were in the second case (No. 3) allowed to elapse after the complete closure of the three large vessels above-named, before the second tracing was taken, and in the third trial (No. 4) thirty beats were steadily counted with the vessels occluded, before the second tracing was obtained. Beyond this I did not feel justified in going, for fear of phlebitic or thrombotic accidents. It will be seen, however, that the change of character in the wave becomes decidedly more marked in each succeeding instance than in that preceding it. IIt consists roughly in the total obliteration of the dicrotic wave termed the "aortic notch." Accompanying this is an increase of rapidity and suddenness in the line of ascent, which, from being nearly vertical in the uncompressed, bends distinctly backwards in the compressed tracings, thus reproducing the circular arc in which the index of the sphygmograph travels. The latter fact might have been anticipated, but the former is curious, and $I$ believe novel. The compressed tracings might be mistaken by an observer not acquainted with their mode of production, for those of a patient in whom the competency of the aortic valves was gravely impaired, and where the reflux of blood into the ventricle, which, in a healthy condition is prevented by their sudden closure, was freely taking place. On the plausible supposition that the dicrotic wave is a return undulation, a sort of echo sent back from the distal extremity of the arterial tree, it may be suggested that the great shortening thus artificially produced in the wave-length of the fluid undulation causes the primary and dicrotic waves to merge into one another.

I may say that neither of my patients felt any inconvenience from the experiment, either during compression or afterwards. An attempt was made to cut the internal iliacs also out of circuit by compressing the abdominal aorta before its bifurcation; but though to a good anatomist like Mr. Pitts the occlusion of this large vessel was not difficult, it caused so much hiccup and respiratory spasm as to render the continuity of the tracing uncertain.

W. H. STONE

\section{THE ELECTRIC LIGHT}

$W^{\mathrm{E}}$ have already referred to the Albert Hall Exhibition, and its important bearing on the progress of electric lighting by bringing together the various methods by which it has been proposed to utilise electricity for this purpose. Since then the newspapers have brought us intimations of further progress which it is stated Mr. Edison has made, and as our readers doubtless know, he has taken out one or more patents for various alleged improvements. We have borne, and will continue to bear, willing testimony to the marvellous ingenuity of Mr. Edison in his application of various scientific principles, resulting in inventions that a year or two ago were scarcely dreant of. We cannot but have the sincerest wish for Mr. Edison's success in whatever he puts his hand to; and his position as an inventor is so high that he needs not to take any trouble to make it more exalted by allowing exaggerated and misleading statements to go forth as to what he is about to do.

We have recently heard a great deal of Mr. Edison's experiments and promises with reference to the electric light. He startled the world in August last by announcing a great discovery which was to revolutionise the modes of artificial illumination at present in use, but we fear his discovery turned out to be something very like a ridiculus mus. Two of his patents have been published; one contains what we must deem a grave scientific error, the other the best authorities consider a mere reproduction of things that have been patented before by Staite, Harrison and others. Up to the present, so far as we can make out, he has done nothing new nor has he produced any- thing practical. The reports of newspaper interviewers are scarcely worthy of attention. Mr. Edison himself complains bitterly of their importunity and irrepressibility; but why, then, does he seem to stamp them with his approval by distributing their reports from his own laboratory? We cannot but think it a misfortune that he has kept at arms' length the electricians of New York, not one of whom, according to his own statement, has been allowed to enter his laboratory. We are therefore entirely dependent upon the New York press for our knowledge of his progress.

$\mathrm{He}$ has laid aside for the present his incandescent light and is experimenting with the Wallace form--his reason being that "everybody knows what the carbon lamp is, and besides it is not my lamp." $\mathrm{He}$ is engaged upon a new dynamo-machine-let us hope not his tuning-fork arrangement-but for what reasons he has put aside such perfect machines as the Siemens and the Gramme we are not enlightened. Dr. Hopkinson has recently shown that the Siemens' machine utilises 90 per cent. of the energy thrown into it. The Gramme is not far behind this. Mr. Edison can scarcely hope to improve on either. Again, the Brush and Wallace-Farmer machines are very efficient. Indeed, we scarcely want to improve the machine for producing currents. It is the lamp that needs the thought and work of the inventor, for no lamp yet exists worthy of the name.

The propagation by the daily press of scientific "discoveries" hot from the brain before they are allowed to be cooled down by the test of experiment is an invention upon which we cannot compliment our American friends. It does not conduce to the progress of science nor does it redound to the credit of the discoverer. We are accustomed on this side of the water to learn of new discoveries through the medium of well prepared and carefully digested papers submitted to one of our societies. There are such societies in America, but the records of such societies have to be searched in vain for any experiments or discoveries of Mr. Edison. We think it is matter for sincere regret that he prefers to promulgate what he conceives to be new through "our special correspondent," and the science dished up by these gentlemen is something wonderful to read. Thus says one paper :-

"Being questioned as to the subdivision of the electric light, the inventor said: 'The question is very simple. If you take a lamp in which the voltaic arc is produced from two carbon pencils, the more current you put on the faster the pencils are consumed and the resistance offered is lessened. There necessarily results a great waste of power. If the lamp is limited to 250-candle-light, it costs too much. By my plan the resistance is almost entirely at the lanip. The resistance of the conductor is to the resistance of the lamp as $\mathrm{I}$ to 100 . The resistance of my lamp is as 192 against $I$ to the resistance of the carbon lamp. You may consider the question most intelligently by taking a gas-burner as an example. If you have a half-inch gas-pipe and light the escaping gas without putting on a burner, how much gas-light can you get from an adjoining burner? Very little. But if you put in the half-inch pipe a burner, with a pin-hole in it, you get a light without interfering with other burners. The same condition obtains in electric lighting. The carbon lamp represents the half-inch gas-pipe; the pinhole burner represents my lamp.' 'But is not the electric current exhausted, not with regard to the resisting agent, but according to the square of the distance travelled?' 'No. If you are supplying a. mile of wire and then add another mile, the current will be weakened equally throughout the whole line, but not to that extent. If you keep on extending your line, you will have to make your conductor thick and add more power.' 'How do you propose to carry this theory into effect?' 'I shall have, proceeding from the central station, where a steamengine and a series of dynamo-machines are placed, a. 
cable, say about an inch in diameter, composed of copper wires, each about one-sixteenth of an inch in diameter. The cable will be laid in a trench immediately under the flagging of the side walk, and near the curb; every twenty-five feet a wire will be dropped to carry the current into a house, and when the terminus of the cable is reached there will be one wire left. Of course it will be necessary to construct the cable according to the number of houses in each district. As a district increases in population the flagging can be taken up, and a section of cable can be placed alongside the original cable, and joined to it at each end. Thus the new houses can be supplied.' 'Will there not be a loss of electricity by induction or the influence of the earth ?' 'None whatever. And now I will tell you another thing. It is perfectly easy for me to get a light equal to sixty-six candles from each of my lamps: but I limit them to six.' 'Will not the construction of your station and your cables be very costly?' 'No; and if it were, the profits would warrant the outlay.'"

Copper wires one-sixteenth of an inch in diameter-the same size as those often used for telegraphic purposesare to convey currents of electricity to light up lamps whose resistances are as 192 to $\mathrm{I}$ as compared with carbon, or as 100 to $r$ as compared with the conductor. The resistance of the copper wire is about 13 ohms per mile. What current will be required to produce a light of 66 candles a mile off under such conditions? An electromotive force of a I,000 volts would not do it, and the very best machines do not much exceed 100 volts in this respect. Where is the power to come from? Mr. Edison now proposes to have 30 of his new dynamo machines worked by his 8o-horse-power steam-engine, lighting up 400 lights. In other words, each machine is to produce about 13 lights, and to absorb $2 \frac{2}{3}$ horse-power. This shows that his experience is gradually bringing him. down to the limits of our experience in France and England, where for some time past one machine lights up twenty lights, but with an expenditure of 23-horse power. It also shows that he was premature in announcing the solution of the indefinite subdivision of the light, and thahe would have done well to have worked upon the expet rience of others rather than have learnt that experience himself by an immense expenditure of time and money. The electric light, theoretically and practically, is unquestionably more advanced in Europe than it is in America. But even here the progress in lamps is very slight.

Col. Bolton, in a remarkable paper read at the last meeting of the Society of Telegraph Engineers, has shown that electric light manias are not only periodic, but that the very same inventions are to a certain extent, also periodic. Thus he showed that everything that Mr. Edison has patented has been patented before in England.

NOTE AS TO DISTINGUISHING CHARACTERISTICS FOR ILLUMINATED BUOYS

THE plan of illuminating by means of Pintsch's system of forcing gas into floating buoys having now been tried by the Trinity House and by the Harbour Authorities of the Tay, I have lately been engaged in considering the best means of distinguishing one buoy from another.

The plan which occurred to me was to make the flow of the gas produce automatic intermittent action, and for this purpose some form of gas meter seemed to promise best. I applied to Messrs. Milne, gas engineers, Edinburgh, to give me their assistance in the matter, and they have succeeded in making a modification of a dry meter which has been tried and found to work very satisfactorily. By this arrangement a small supply of gas keeps a small jet constantly illuminated a little above the principal burner, and when, by the valve, the full supply of gas is turned on to the large burner, it is ignited by the small jet. The periods of light and darkness can be regulated in any desired proportion. The same object may, however, be effected by means of a single burner, the jet being kept burning in the socket.

By means, then, of two separate lanterns, one of which has red panes, and the other either white or green, the following characteristics may be produced :-

Red and white.

Red and green.

Green and white.

If, again, only one lantern be used, we shall haveIntermittent white.

$$
\begin{aligned}
& \text { " red. } \\
& \text { " green. }
\end{aligned}
$$

And if to these we add the present single fixed white, red, and green, this would give in all nine characteristics, which would probably be sufficient for any navigation.

It is proper to add that, in order to prevent oscillations of the apparatus, which would take the light out of the sailor's vision, the apparatus and burner should be made to work in gimbals, as in my steamer's lights. If these gimbals were made hollow, the gas could be easily made to pass up to the burner, but a simpler mode would be to use a flexible tube between the regulator and the burner.

THOMAS STEVENSON

\section{GEOGRAPHICAL NOTES}

LETTERS from Nordenskjöld have been received by the Governor-General of Siberia. They confirm the news already brought to Europe. The Vega steamship has been blocked by ice in a harbour named Kamen, at a short distance from Behring Straits on the east coast of Siberia. This station is easily reached by whalers every year. No doubt the escape of the explorer and his companions will take place without difficulty as soon as the ice breaks up, probably in $a$ few weeks. The news has been brought by native messengers, and everything was going on well on board the Vega.

M. WOEIKOF has sent to the French Geographical Society a long and exhaustive memoir on the Oxus question. After having studied the question on the spot, the Russian geographer feels certain that the suppression of the Caspian mouth was produced not by a gracual elevation of the country, but by the accumulation of deposits in the bed of the river, and the immense drainage produced by the development of irrigation in the Khivan Oasis. He feels certain that the restoration of the former state of things would be a very easy work. It would result in the establishment of a new oasis between Khiva and the Caspian Sea. The Oxus being navigable to Balkh, and the Volga being in direct communication with the Baitic, through a system of canals, a water-way would thus be established from St. Petersburg to Balkh, and the stream would connect the Russian capital with the vicinity of their scientific frontier of India. M. Woeik of supposes justly that the restoration of the Cxus to the Caspian would accelerate the retreat of the Aral waters. He believes that shortly after that large operation the area of Aral would be reduced to one-third of its present extent. But he argues that this alteration would not be altogether detrimental to the prosperity of the surrounding countries.

THOUGH there are no joumeys of discovery into the interior to record, some useful geooraphical and topographical work was done in Western Australia by the Surveyor-General's department during the last six months of I 878 , as we learn by a report just received from Perth. The position of Mount Welcome at Roebourne, on the north-west coast of the colony, was determined to be 